\title{
Phenology and pollinating wasp dynamics of Ficus microcarpa L.f.: adaptation to seasonality
}

\author{
Hui-Wen Yang ${ }^{1}$, Hsy-Yu Tzeng ${ }^{2}$ and Lien-Siang Chou ${ }^{1 *}$
}

\begin{abstract}
Background: In the obligate plant/pollinator mutualism, pollinator abundance is conditioned by the host resource. In order to investigate the population fluctuation of pollinating wasps and the phenological processes involved, this study examined the dual dynamics of the pollinator and the syconium phenology of a seasonal fruited fig tree population, Ficus microparpa, in Taipei, Taiwan.

Results: Our results revealed three seasons in the annual phenology: spring crop, summer-fall crop and winter trough seasons. The syconium quantity was correlated most significantly with temperature based on the generalized linear model with the meteorological data transformed by a principal component analysis. The pollinator population showed an increasing trend in spring, reached the maximum abundance in summer, and then declined drastically in winter, consistent with the syconium production fluctuation. With the small amount of local pollinators from the winter syconia and potential immigrating foundresses from other populations, the pollinator population size can increase very quickly from almost zero to over 40,000 wasps for this 29-tree local population within a season.
\end{abstract}

Conclusion: This syconium phenological scheme, coupled with the fast-recovery rate of pollinators, may explain the worldwide adaptation and invasion of Ficus microcarpa.

Keywords: Eupristina verticillata; Ficus microcarpa; Fig wasp; Insect population dynamics; Invasive plant; Mutualism; Phenology; Pollination ecology

\section{Background}

Pollination success is the main determinant of the fitness of the plant kingdom. Vegetal species pollinated by insects have developed numerous strategies to attract insects and transport their pollen to conspecific individuals, driving the evolution of angiosperms ( $\mathrm{Hu}$ et al. 2008; Thien et al. 2009). However, variations in the schemes of host phenologies may result in pollination failure (Winder and Schindler 2004; Durant et al. 2007; Jonzen et al. 2007; Martin 2007). The generalist pollinating species would be less affected by these changes for they can visit a greater range of flowering plants than more specialized pollinators. More specifically, extreme specialists, such as the obligate mutualistic species, are bound to their hosts. In these cases, both species require the other for survival and to accomplish their life cycle. Changes in the abundance

\footnotetext{
* Correspondence: chouls@ntu.edu.tw

${ }^{1}$ Institute of Ecology and Evolutionary Biology, National Taiwan University, No. 1, Sec. 4, Roosevelt Rd., Taipei 10617, Taiwan

Full list of author information is available at the end of the article
}

of any of the partners could drastically reduce their fitness (Visser and Both 2005).

The genus Ficus exhibits one of the most extreme obligate nursery mutualisms, with plant pollination performed by Hymenopteran wasps (Agaonidae sensu Cruaud et al. 2010). The characteristic shared by the Ficus trees is an enclosed urn-shaped inflorescence called the syconium (also known as a fig), with dozens to thousands of unisexual flowers inside. The only entrance to the syconium lumen is a narrow, bract-surrounded channel, called an ostiole, which has evolved to only allow the entrance of the fig's species-specific agaonid wasps (Wiebes 1979; van Noort and Compton 1996). Inside, the female wasps pollinate the flowers as they oviposit their eggs. Their larvae then feed on the galls they have induced (Kjellberg et al. 2005). A few weeks later, the wasp offspring emerge simultaneously when the male flowers mature. After mating they leave their natal syconium to find a new receptive one. Since the pollinator lifespan is extremely short, usually only a few hours to two days (Kjellberg et al. 1988; 
Dunn et al. 2008; Wang et al. 2009), the newly emerged pollinator has to enter another available syconium within a short time period. Thus a continuous syconium crop presence would be necessary to sustain a local pollinator population.

However, variability in environmental conditions (e.g., low temperature, dry season, etc.), which decrease syconium production (Kjellberg et al. 1987; Spencer et al. 1996; Chen et al. 2004; Tzeng et al. 2006), also dramatically decrease pollinating wasp populations and can even result in a local extinction of these pollen carriers (Bronstein 1995; Harrison 2001; Bain 2012). While the cited studies have already established the environment syconium production - pollinating wasp dynamics, none have described the trajectory of the pollinating wasp population in detail or explored the relationship between its recovery rate and the syconium phenology during seasonal conditions.

Ficus microcarpa is a widely distributed species planted worldwide. Its adaptability has allowed it to colonize various environments such as the American continent, the Hawaiian archipelago, and the South of Europe (McKey 1989; Kaufmann et al. 1991; Nadel et al. 1992; Doğanlar 2012). The associated pollinating wasp species of $F$. microcarpa, Eupristina verticillata Waterston has been observed in many places where F. microcarpa was introduced (Kaufmann et al. 1991; Beardsley 1998; Doğanlar 2012). The invasion of $F$. microcarpa seedlings indicates that the pollinators work efficiently. What are the characteristics of the tropical F. microcarpa that make it an efficient invasive species even in strongly seasonal areas such as North America? What are the phenological advantages that allow $F$. microcarpa to maintain its pollinating wasp population in its distribution area and in newly colonized lands?

In this study, we focus on a Ficus microcarpa population in Taipei, Taiwan where seasonality in syconium abundance was recorded (Hsieh 1992; Chen et al. 2004). The phenologies of both the mutualists, the syconium abundance and the pollinator population dynamics, were studied at the same time over a 14-month survey. The aim was to investigate the dual cycling of populations of figs/ fig wasps to explore their adaptive strategy for seasonality.

\section{Methods}

\section{Study species}

Ficus microcarpa L.f. (subgenus Urostigma, section Conosycea) is a large evergreen, hemi-epiphytic monoecious tree with abundant aerial roots. Syconia are found axillary, singly or in pairs (Hill 1967; Tzeng 2004; Berg and Corner 2005). Ripe syconia measure about 6$10 \mathrm{~mm}$ in diameter, turning from reddish green to pink or purple, and are consumed by more than 200 frugivorous vertebrate species, mainly birds and some fruit bats
(Shanahan et al. 2001). Ficus microcarpa is natively distributed from Southern and Eastern Asia to Northeastern Australia (Hill 1967; Chew 1989; Berg and Corner 2005). This species is also native to Taiwan where it is a common roadside tree in all urban areas. Ficus microcarpa is pollinated by the pollinating wasp Eupristina verticillata Waterston (Hymenoptera: Agaonidae sensu Cruaud et al. 2010) (Chen et al. 1999). Like many monoecious Ficus species, most $F$. microcarpa trees produce synchronous crops. However, some level of asynchrony within the same branch or among different parts of the tree crown has been reported in past studies (Hill 1967; McPherson 2005a; Lin et al. 2008; Yang 2011).

\section{Study site and climate}

In order to investigate the typical $F$. microcarpa urban trees, 29 trees were surveyed along a $250 \mathrm{~m}$ stretch of road by the National Taiwan University campus in Taipei, Taiwan $\left(25^{\circ} 00^{\prime} 43^{\prime \prime} \mathrm{N}, 121^{\circ} 32^{\prime} 25^{\prime \prime}\right.$; $21 \mathrm{~m}$ above sea level). These trees are more than 25 years old, with heights ranging from 7 to $14 \mathrm{~m}$.

Taipei has a humid subtropical climate. February to October is classified as a very moist period, while November to January is classified as a relatively moist period (Figure 1).The meteorological definition of seasons by the Central Weather Bureau (www.cwb.gov.tw) was adopted in this study: spring: March to May; summer: June to August; fall: September to November; and winter: December to February. The average temperature is $22.7^{\circ} \mathrm{C}, 29.4^{\circ} \mathrm{C}$ in summer and $18.1^{\circ} \mathrm{C}$ in winter (Taipei meteorological station in the Central Weather Bureau). Summers are humid and accompanied by occasional rainstorms and typhoons, while winters are short and mild.

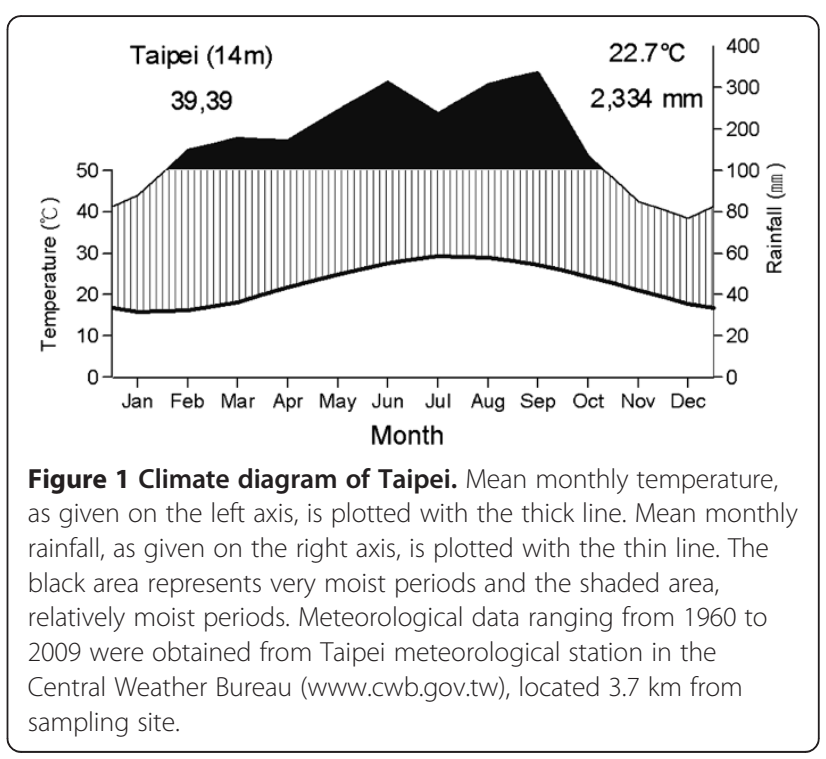




\section{Syconium developmental stage classification}

The development of syconia was classified into 5 stages according to Galil and Eisikowitch (1968). In the A phase, the syconium initiates and the female flowers grow inside. In the case of $F$. microcarpa, this period lasts about 0.5 to 1 week (Chen et al. 2004). The B phase is the female phase when female flowers mature and emit volatile compounds which attract pollinators (HossaertMcKey et al. 1994; Gibernau et al. 1998; Grison-Pigé et al. 2002; Proffit et al. 2008). This is the only period during which pollinators can enter the syconia. The length of this period is typically 0.5 to 1 week, and can be extended to 2 weeks if pollinators do not enter the syconium and pollinate the flowers (Chen et al. 2004). In the $C$ phase (interfloral phase), seeds and galls develop inside the syconia. This development takes 2 weeks in summer and fall, and 4 weeks in spring and winter. The D phase is the male phase: fig wasp offspring emerge while male flowers mature. Then female fig wasps loaded with pollen grains exit the syconia. In F. microcarpa, as in numerous other Ficus species, the D phase is short, lasting for a few hours to one day (Yang, unpublished data). During the following 1 to 3 days, the syconia drastically change in appearance from greenish pink at the wasps' emergence to dark purple. This is the E phase where seeds mature and are ready to be dispersed. The purple syconia mainly attract birds in Taipei (Yang, pers. obs.). Although both D and E phases are mainly short, there exists developmental asynchrony among syconia of the same tree (Hill 1967; Lin et al., 2008; Yang 2011), and thus we can observe D or E-phase syconia on a tree for around 1 to 2 weeks.

\section{Phenological censuses}

We conducted phenological censuses from May 2008 to July 2009, visiting each of the 29 trees at a weekly interval (the average was 8.2 days between censuses). During each survey, we cut down four branches from each tree; each branch was randomly selected from one of the four ordinal directions (North, South, East and West) of the tree crown. In this study, we used a 30-50 cm long branch located at a height of $2-5 \mathrm{~m}$ as our sampling unit. We recorded the number and developmental stage of the syconia in each sample. If we encountered late B or $\mathrm{C}$ phase syconia, we brought them back to the laboratory for further investigation of the foundress number.

During each survey, we also recorded the proportion of syconium-bearing branches on each tree. First, we divided the tree crown into 4 ordinal parts in similar locations where the sample branches were taken. Then, we estimated the proportion of syconium-bearing branches in each part. The estimations were categorized into 5 classes: $1=$ less than $25 \%$ of branches bearing syconium, $2=$ about $25 \%$ bearing syconium, $3=$ about $50 \%, 4=$ about $75 \%$, and $5=$ about $100 \%$. We directly counted the syconium-bearing branches in all class 1 parts. We then used this data for the estimation of foundress population size as described in the following method. To estimate the total number of branches on the tree crown, we took numerous photographs of each tree on November 26, 2010. We carefully counted the number of branches from the digital images with image processing software (Adobe Photoshop CS3). In cases where it was difficult to take good quality photographs of some parts of the trees for a reliable count, we estimated the number of branches based on the average count of the other parts. We observed that the trees grew slowly and were trimmed once a year in spring and thus we assume that the variation in the number of branches during the survey period was small enough to be neglected.

\section{Foundress population monitoring}

In this study, we regarded the syconia as natural biotraps for pollinators. As such, we used the number of foundresses trapped in the B- or C-phase syconia as an indicator of the pollinating wasp population in the local environment. We considered this as a reliable indicator based on two assumptions. First, the number of foundresses in a given syconium is positively correlated with the current and local wasp cloud (i.e. the free-flying pollinators yet to enter a receptive syconium). However recent studies proved there is a density-dependent ostiole enclosure (Wang et al. 2009). When the foundress number is high, the ostiole closes more quickly to avoid too many foundresses. In this case, the foundress number might be saturated, and thus we tend to underestimate when there is an abundance of pollinator wasps. Second, although some foundresses could exit from a syconium after entering (Gibernau et al. 1996; Chen et al. 2001), the vast majority of the observed foundresses are positively correlated with the actual number of foundresses that had entered the syconia. The foundress number was previously used in several studies to reflect the effect of syconium seasonality (Bronstein and Hossaert-McKey 1996; Wang et al. 2005; Wang and Sun 2009). However, the weekly abundance, as presented in this study, was only seen in the study of Bronstein and Hossaert-McKey (1996).

We took the B and C phase syconia from the sample branches and cut them open to count the number of foundresses under a stereomicroscope. Although some foundresses might be mangled during the syconium development, they would not be decomposed, and thus were able to be pieced back together. We identified and recorded the phase of the sampled syconia. To ensure all potential pollinators had entered, only syconia in the late $\mathrm{B}$ phase or early $\mathrm{C}$ phase were analyzed. Foundresses in 8,073 syconia from 862 branches (28 trees, as one never fruited) were counted during the study period. 


\section{Data analysis}

A crop was defined as the succession of syconia from phases A to E for each tree. Sometimes trees can start a new crop before the previous crop was finished and is denoted as another overlapping crop. The period when an individual tree does not bear any syconia is called a flowering interval.

In this study, we also attempted to investigate the relationship between meteorological factors and syconium productivity. We considered three meteorological variables in this study: daily mean temperature, daily rainfall, and daily sunshine hours. We obtained these data from the Taipei meteorological station, located $3.7 \mathrm{~km}$ away from the study site. We then used the inter-survey average of the temperature and sunshine hour and intersurvey rainfall sum (for the first survey, we took a 7-day interval) for correlation tests. Principle component analysis (PCA) was used to identify and explore covariance patterns among meteorological factors. In the PCA, a correlation matrix was used. We tested the significance of each loading (eigenvector coefficient) by the bootstrap-confidence interval method (Peres-Neto et al. 2003).We performed a generalized linear model (GLM) with negative binomial error ( $\mathrm{R}$ software, $\mathrm{R}$ Development Core Team 2009) to explore the correlation between syconium production in each phase and the principle components (PCs) of the meteorological data. Since the syconium developmental phases are progressive, we included the previous phase as a covariate for the B, C, D and E phase with a 1- or 2-week delay effect (depending on which one has higher correlation coefficient). In order to prevent the extremely high amount of rainfall brought by typhoon Sinlaku from influencing the results, the survey following the passage of typhoon Sinlaku (September $17^{\text {th }}$ ) was not incorporated in the analysis.

In order to represent the foundress dynamics in a different aspect, we developed four foundress indexes. Previous studies simply adopted "average foundress number," which is the total number of foundresses divided by total sampled syconia (e.g. Bronstein and Hossaert-McKey 1996; Wang et al. 2005; Wang and Sun 2009) to reflect the foundress abundance. Here we separated the pollination frequency into two levels, the tree (individual) as well as the syconium level. In addition, the crowdedness of foundresses inside each occupied syconium should also be considered. Thus, we developed the following four indexes for each survey:

(1) Proportion of pollinated trees: the proportion of trees receiving pollinators among all receptive trees.

(2) The occupation rate: the proportion of syconia entered by foundresses among all dissected late B- ore early C-phase syconia on a given branch.
(3) Crowdedness index: the mean number of foundresses in occupied syconia on a given branch.

(4) Foundress population size: the approximate size of the pollinator cloud (the free-flying pollinators yet to enter a receptive syconia) of each survey, which was calculated by the number of foundresses sampled multiplied by the estimated number of total B-phase syconia:

$$
\text { Foundress population size }=\sum_{j=1}^{29} \sum_{i=1}^{4} b_{i j} f_{i j} a_{i j}
$$

where $i$ represents the ordinal parts (1-4) of the tree, and $j$ represents the number of the tree (1-29). $b_{i j}$ is the number of syconium-bearing branches at side $i$ of tree $j, f_{i j}$ is the number of syconia in the late $\mathrm{B}$ phase or early $\mathrm{C}$ phase, and $a_{i j}$ is the average number of foundresses on the sampled branch, calculated by multiplying the occupation rate and the crowdedness index. In the instances when foundresses were not sampled from one to three sides of the tree crown, we used the average foundress number of all other sides on the same tree to represent $a_{i j}$ for these sides. The number of syconium-bearing branches $\left(b_{i j}\right)$ for each tree direction, in reference to the 5 classes (see above) recorded in the field survey, is equal to either the actual counts of the branches in the case of class 1 , or the product of the proportion of syconiumbearing branches and the total number of branches in the cases of classes 2-4.

\section{Results}

\section{Phenology of syconium production}

Syconia of Ficus microcarpa were present year-round, with obvious high yield and low yield seasons (Figure 2). A total of 158 crops were recorded from 29 fig trees. Individual trees produced 0-9 crops with an average of $5.4 \pm 2.7$ (mean \pm SD) crops during the period of the 14-month survey, equivalent to 4.7 crops per year. There were two main syconium production periods: from July to October 2008 and mid-February to May 2009 (Figure 3f). Between them was a winter trough lasting two months. Thus, we classified the syconium phenology into three periods: the spring crop season, the summer-fall crop season, and the winter trough.

The spring crop season started with the increase in temperature when the winter ended (Figure 3a, f). The syconium development took 4 to 12 weeks (Figure 2). Nineteen of these trees were recorded as bearing syconia in the A or B phase over several successive surveys, which revealed a continuous production of new syconia for several weeks. This accounted for an immense number of Aphase syconia in this period (Figure 3a). Two peaks of D- 


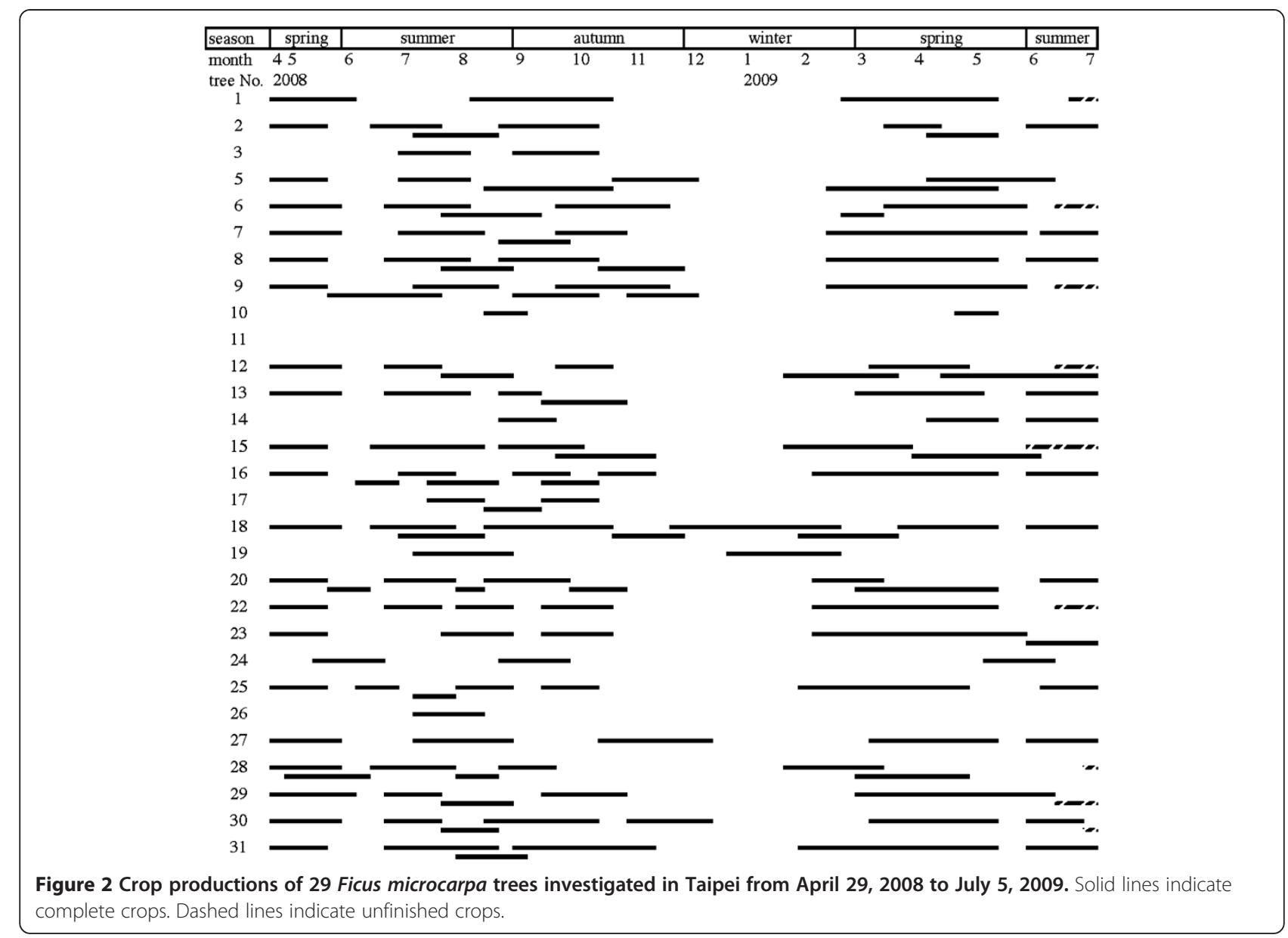

phase syconia were observed: a small one at the end of March, and a larger one in mid-May. The trees then entered the flowering interval lasting 2 to 4 weeks (Figure 2). The summer crop season started in June (both 2008 and 2009). The syconium development was relatively shorter during this period and took about 4 weeks to finish a cycle. The syconium quantity decreased gradually in fall, and the last D-phase peak resulting from the end of 4 trees' crops occurred in December. All except 2 trees stopped producing new syconia after November, and went into a long flowering interval lasting 2 to 3 months (Figure 2).

\section{Correlation with meteorological factors}

The first principal component (PC1) explained $55.29 \%$ of the meteorological variability and was closely related to temperature (loading $=0.7054, p<0.01$ ), while the second component (PC2), explaining $33.13 \%$ of the variance, was positively related to sunshine hours and was negatively related to rainfall (Table 1). In terms of the correlation between syconium abundance and meteorological factors, the syconium abundance of total counts and all phases except the A-phase were positively correlated with PC1 (all $p s<0.05$, Table 2). Furthermore, only E-phase syconia showed a positive correlation $(p<0.05)$ with PC2.

\section{Pollinator abundance}

Among the 862 sampled branches from the different surveys, the occupation rate (i.e., the proportion of syconia occupied by pollinators) varied from 0 to 1 , and the crowdedness index (number of foundress in the occupied syconia) varied from its minimum of 1 up to 9.2. The estimated foundress population size ranged from 0 to 45,957 . All the foundress indexes varied greatly during the survey (Figure 4).

During the spring crop season, the proportion of pollinated trees increased steadily (Figure 4a), and the occupation rate increased from $0-0.4$ in February to 0.9 in May (Figure 4b), with an average of 0.2. However, the crowdedness index remained at an average of 1.2 (Figure 4c). These indicated that the number of receiving syconia was greater than the available pollinators. The occupation rate, average foundress number, and estimated foundress population size decreased in June 2008 and 2009 during the flowering intervals of numerous trees. However, all the 


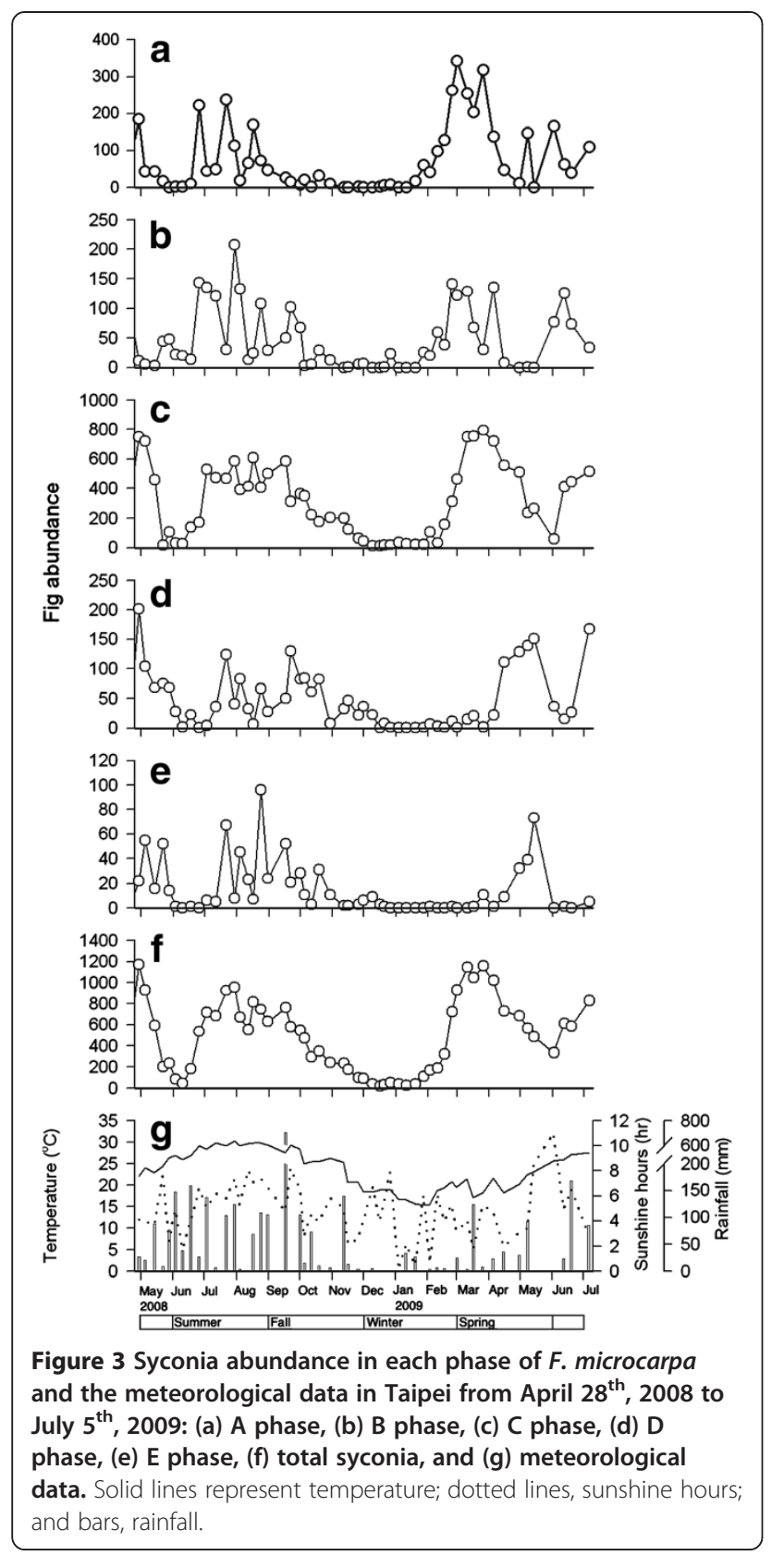

Table 1 Principal component analysis for the three meteorological factors

\begin{tabular}{lccc}
\hline Variables & PC1 & PC2 & PC3 \\
\hline Eigenvalue & 1.6586 & 0.9938 & 0.3476 \\
Explained variance of PC (\%) & 55.29 & 33.13 & 11.59 \\
Meteorological factors & & & \\
Rainfall & 0.4632 & $-0.7578^{* *}$ & -0.4595 \\
Temperature & $0.7054^{* *}$ & 0.0014 & $0.7088^{* *}$ \\
Sunshine hours & 0.5365 & $0.6525^{* *}$ & -0.5352 \\
\hline
\end{tabular}

Asterisks flowing the loadings represent the significance level: ${ }^{*} p<0.05$, ${ }^{* *} p<0.01,{ }^{* * *} p<0.001$.
Table 2 Correlation between meteorological factors and the abundance of syconia+

\begin{tabular}{lllll}
\hline Syconium phase & Covariance & PC1 & PC2 & PC3 \\
\hline A & None & 0.0300 & 0.0905 & -0.1493 \\
B & A, 1-week delay & $0.3211^{*}$ & -0.0327 & $1.1363^{* * *}$ \\
C & B, 2-week delay & $0.3198^{* * *}$ & -0.0684 & -0.1052 \\
D & C, 2-week delay & $0.2110^{*}$ & -0.0953 & 0.1024 \\
E & D, 1-week delay & $0.4988^{* * *}$ & $0.4667^{* *}$ & -0.01812 \\
Total syconia & None & $0.2110^{*}$ & -0.0953 & 0.1024 \\
\hline
\end{tabular}

Asterisks represent the significance level: ${ }^{*} p<0.05,{ }^{* *} p<0.01,{ }^{* * *} p<0.001 .+$ The variables used in the correlation was transformed by a principle component analysis.

indexes recovered to a higher value in July in both 2009 and 2008 (Figure 4).

The weekly pollinator indexes were highest from July to October (Figure 4). The average occupation rate was 0.6 and ranged from 0.2 to 0.9 (Figure $4 \mathrm{~b}$ ). The crowdedness index was 2.0 on average. The estimated foundress population size was greater than 30,000 in July 2008 (Figure 4d). Although there was a drastic decline in August, occupation rates recovered in the following month, but the crowdedness indexes dropped afterwards (Figure 4c). The estimated foundress population size kept decreasing from fall to winter, indicating a decline in pollinator population during this period.

The four pollinator indexes were low during the syconia production trough. The production of new syconia was intermittent from December to February and thus resulted in a lack of data in some weeks. Based on available data, occupation rates during this period were low (Figure 4c). Only one tree (Number 19) that grew new syconia in January was pollinated successfully. Estimated foundress population size was less than 200 during this period.

Estimated foundress population size was positively correlated with D-phase syconia abundance (Pearson correlation test, both variables were $\log$ transformed, $p<0.001, R^{2}=0.45$, Figure 5$)$. Note that there were two weeks where no D-phase syconia were observed but the foundress population sizes were not zero (Figure 4d). These two weeks revealed pollinator immigration events, which happened at the start of the summer-fall flowering season (July 25, 2008), and also in the winter trough (January 3, 2009).

\section{Discussion}

Our study showed the dual dynamics of syconium abundance and the pollinating fig wasp population and established the correlation between them. The phenology of Ficus microcarpa in Taipei tracked seasonal variations, which can be separated into the spring flowering season, the summer-fall flowering season, and winter trough. The corresponding pollinating wasp population 

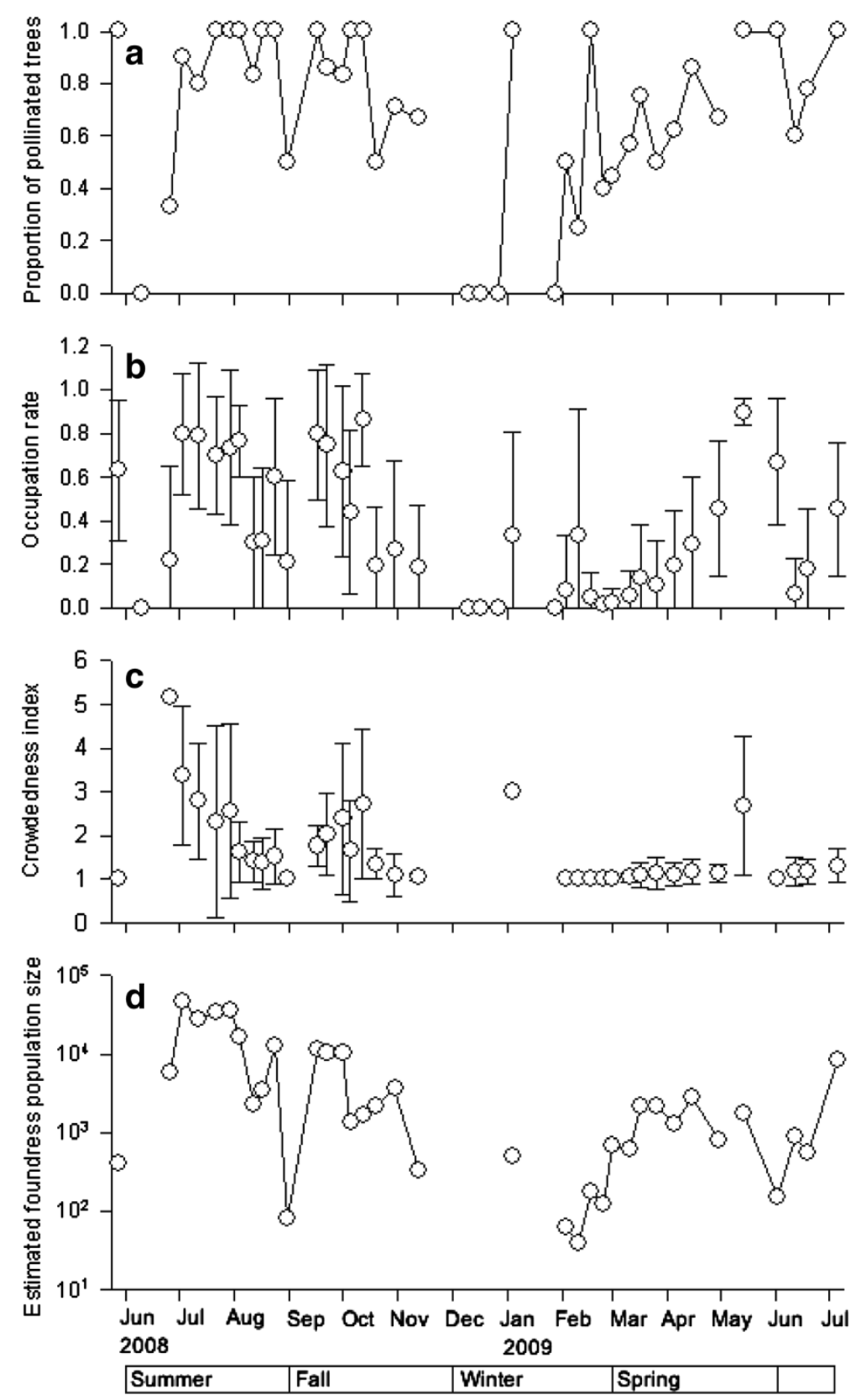

Figure 4 Pollinator indexes of F. microcarpa in Taipei from May 27, 2008 to July 5, 2009: (a) Proportion of pollinated tree, (b) Occupation rate, (c) Crowdedness index, and (d) Estimated foundress population size in study area. Vertical bars in (b) and (c) indicate standard deviation.

expanded in spring, maximized in summer and then shrank to a very low level in winter.

We found that PC1, which showed a significant high loading on temperature, was the most significantly correlated factor with syconium abundance, suggesting that this is an important factor determining the phenology of F. microcarpa in Taipei. A higher syconim yield in warm seasons was also reported in several other studies of $F$. microcarpa in other subtropical areas, as summarized in
Table 3. In this study, the $\mathrm{B}, \mathrm{C}, \mathrm{D}$, and $\mathrm{E}$ phases were positively linked with temperature and also with pollinating wasp activity. Numerous studies showed the positive effects of temperature on insect activity (Willmer 1983, 1985; Kalin Arroyo et al. 1985), which is congruent with the number of $\mathrm{C}$-phase syconia, which are the consequence of pollination. Also, temperature has a clear effect on Hymenoptera larval development (Ando et al. 2006; Dhillon and Sharma 2009) and seed maturation 


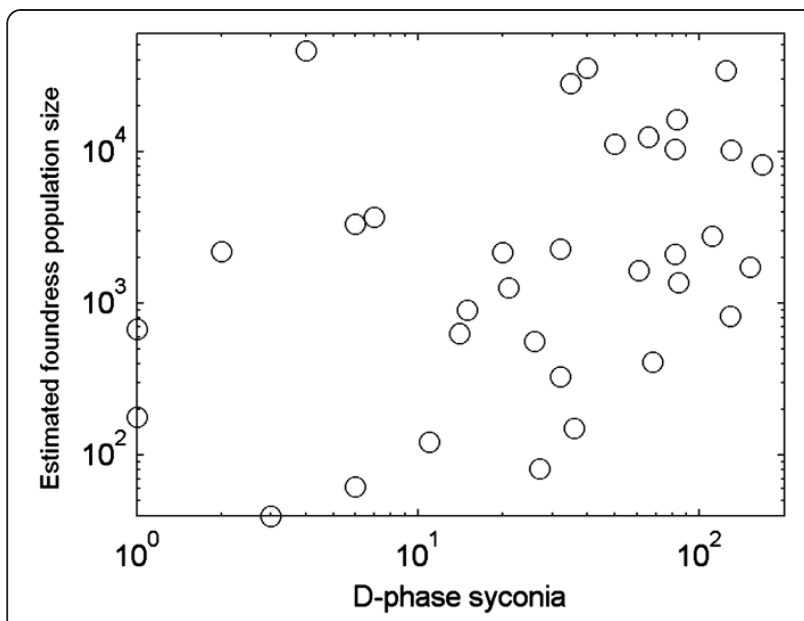

Figure 5 A plot of estimated foundress population size versus D-phase syconia quantity. The correlation between these two variables was significant $(p<0.05)$. There were two weeks in which no D-phase syconia were censused but foundress population size was not zero. These took place on July 25, 2008 and January 3, 2009 respectively.

(Bronstein and Patel 1992; Tzeng et al. 2005; Ellis 2011), which are the processes involved in the $\mathrm{D}$ and $\mathrm{E}$ phases. In addition, $\mathrm{PC} 2$, which is positively linked to sunshine hours and negatively to rainfall, was statistically correlated with the abundance of E-phase syconia, the seed dispersal phase. The effect of light has been documented to be an important factor for the ripening of a wide range of plant species (Wright and van Schaik 1994; Zimmerman et al. 2007). Thus, the Ficus species do not deviate from the general pattern of fruit ripening.

The substantial crops in spring provide favorable conditions for their pollinating agents to expand after the drastic population drop in winter. Considering the high reproductive potential of the pollinating wasps (20-80 offspring per foundress, Chen 2001), the pollinator population has the ability to grow exponentially. Our estimated foundress population size coincides with the theoretical logistic growth pattern of a population, with exponential growth in spring and the saturation period in summer (Figure 3e).

The abundance of syconia in spring was also recorded in previous studies in Taipei (Hsieh 1992; Chen et al. 2004), as well as in Hong Kong (Hill 1967) and in Brisbane (McPherson 2005a) (Table 3). In fact, the simultaneous production among trees might be a general physiological response of fig trees after harsh conditions, since it has been reported after extreme climatic events, such as tropical cyclones (Bronstein 1995; Bain 2012) and ENSO-induced droughts (Harrison 2001), and the occasional unfavorable season (Kjellberg et al. 1987; Tzeng et al. 2006; Spencer et al. 1996). After a period of low syconium density, pollinating wasps are rare. The immense crops following harsh conditions can be seen as an investment from the trees. The bigger the crop is, the greater the chance to attract a pollinating wasp. Once these trees were visited, the first-generation offspring of pollinators have a high likelihood of pollinating other syconia (number of receptive syconia is greater than the number of pollinators) with a weaker pollen competition (the crowdedness index remained at 1.2). Thus, the benefits from their male function, pollen production, may offset the cost of being unpollinated.

Compared to the spring crops, the summer-fall crops may benefit more from their female function, seed production. Previous studies of $F$. microcarpa reported an abundance of seed production two times greater in the summer-fall season than in the spring season. For example, the proportion of seeds per syconia was $23.8 \%$ during the summer-fall but only $9.7 \%$ during spring seasons respectively at Taipei (Chen 2001); the average number of seeds was 10.63 and 28.77 in June and September, respectively, but only 4.09 and 5.15 in March and December, respectively at Guangzhou, China (Lin et al. 2008). Furthermore, a higher temperature shortens the duration of syconium development (Bronstein and Patel 1992; Chen et al. 2004; Tzeng et al. 2005; this study) and enables more crops, allowing even more seeds to be produced.

Our study also revealed another adaptive strategy for maintaining the fig/fig wasp mutualistic relationship. Several studies focused on the sustainability of the pollinator population in winter, approaching from the perspective of the minimum required population size (Bronstein et al. 1990; Anstett et al. 1995, 1997). Here in Taipei with distinct seasonal changes, we showed that a small number of pollinating wasps could spark the whole summer population. In Taipei, Ficus microcarpa succeeds in reserving the pollinators by bearing syconia on a few trees (Hsieh 1992; this study) and sheltering the pollinator larvae in C-phase syconia during the cold and rainy seasons. In other locations where $F$. microcarpa trees cannot bear syconia in winter due to environmental conditions, the wasp population might be sparked by the migrants, which is not a problem since the tiny agaonid wasps are excellent gliders (Compton et al. 2000, Harrison and Rasplus 2006) that can travel more than $100 \mathrm{~km}$ (Ahmed et al. 2009). Thus, an occasional local extinction and wasp irruption will occur, and the reproduction of $F$. microcarpa can still be assured in some seasons, as was the case reported in Brisbane (McPherson 2005b) where seeds in F. microcarpa syconia were found in May to July but not in August (the last month in winter).

Ficus microcarpa has been documented as an invasive species in many places where it was initially planted for ornamental use (McKey 1989; Nadel et al. 1992; 


\section{Table 3 Phenology studies on Ficus microcarpa}

\begin{tabular}{|c|c|c|c|c|c|c|c|}
\hline Study site & Study year & $\begin{array}{l}\text { Duration (mo)/ } \\
\text { interval (day) }\end{array}$ & $\begin{array}{l}\text { Number } \\
\text { oftrees }\end{array}$ & Phenology & $\begin{array}{l}\text { Crops produced per } \\
\text { tree per year }\end{array}$ & Crop length & Reference \\
\hline Hong Kong & Jan-Nov 1964 & $11 / 14-30$ & 20 & $\begin{array}{l}\text { Continuous production by species as a whole and by many } \\
\text { individuals. All trees had a large crop in spring. } 90 \% \text { had a } \\
\text { second crop in summer. }\end{array}$ & $1-5$, most 3-4 & 1-4 months & Hill 1967 \\
\hline Singapore & Oct. 1982-Feb 1984 & $17 / 7-17$ & 8 & No clear pattern. & 2-6, mean 4.4 & 30 days & Corlett 1984 \\
\hline Taipei (Taiwan) & Jan. 1991- Feb. 1992 & $14 / 7-10$ & 84 & $\begin{array}{l}\text { Continuous production with main peaks in } \\
\text { Apr.-Jan and Jul.-Sep. }\end{array}$ & $0-4$, most 2-3 & 26 days in June & Hsieh 1992 \\
\hline Sao Carlos (Brazil) & Mar. 1991- Feb. 1992 & $12 / 15$ & 19 & $\begin{array}{l}\text { Continuous production; syconia and leaf production were } \\
\text { sequentially related. }\end{array}$ & $2.26 \pm 0.81($ meant $\pm S D)$ & 110.75 days & Figueiredo et al. 1995 \\
\hline Taipei (Taiwan) & Aug. 1992- Nov. 1998 & $76 / 7$ & 35 & $\begin{array}{l}2 \text { gaps: late Apr. to early May, lasting } 3 \text { weeks; late Oct. to } \\
\text { Feb lasting } 5.8 \text { weeks. Positive correlation with temperature } \\
\text { but not rainfall. }\end{array}$ & 2.1 , with $25 \%$ aborted & 5.97-10.28 weeks & Chen et al. 2004 \\
\hline Brisbane (Augstralia) & Sep. 1997- Aug. 2001 & $48 / 30$ & 8 & $\begin{array}{l}\text { Female phase: Late spring peak; Male phase: more present } \\
\text { in warmer months. }\end{array}$ & No records & No records & McPherson 2005a \\
\hline Guangzhou (China) & Mar. 2005- Sep. 2006 & 19/1/7-14 & 10 & $\begin{array}{l}\text { Higher proportion of each phase from Aug. to Sep. and } \\
\text { Nov. to Mar. A, B, C phase is negatively correlated } \\
\text { with temperature }\end{array}$ & $1-4$, most 3-4 & $1-2$ months & Lin et al. 2008 \\
\hline
\end{tabular}


Beardsley 1998; Doğanlar 2012). The data presented in this study uncovers at least three advantageous characteristics for adapting in an invasive condition. First, the pollinating wasps can greatly increase their population from one single crop. Second, they do not seem to enter syconia when other female wasps are inside but instead migrate to other available syconia, thus maximizing the reproductive outcome. This was supported by the crowdedness index which did not follow the increasing trends of occupation rate or fig tree proportion loaded with pollinators. Finally, the pollinating wasps for Ficus mircrocarpa must be good travelers. Therefore, with the above advantageous characteristics and through a dual cycling fluctuation in syconium phenology and wasp population dynamics, F. microcarpa has become an adaptive and invasive fig species worldwide.

\section{Conclusion}

The present study showed a dual cycling in phenological patterns of fig production and wasp population dynamics to adapt to seasonal climate changes in northern Taiwan. Responding to the seasonal changes in climate, Ficus microcarpa at Taipei exhibited three seasons in its annual phenology: the spring crop, summer-fall crop and winter trough seasons. With the small amount of pollinators from the winter syconia of the same fig population and potential immigrated foundresses from other populations, the pollinator population size can increase very quickly from almost zero to over 40,000 wasps for this 29-tree local population within a year. Some advantageous characteristics have pre-adapted $F$. microcarpa into a good invasive fig species around the world.

\section{Competing interests}

The authors declare that they have no competing interests.

\section{Authors' contributions}

LSC directed the goals of the study, guided the research design and interpretation, and managed the funding. HYT co-designed the statistical methods. HWY conducted all field work and data analysis and was in charge of manuscript writing, with revisions made by LSC and HYT. All authors read and approved the final manuscript.

\section{Acknowledgments}

We are indebted to Dr. I-Fang Sun, Dr. Wen-Jer Wu and Dr. Anthony Bain for their generous suggestions during the drafting stages of this manuscript. We are also grateful to the two anonymous reviewers for their thoughtful and invaluable comments. We thank Dr. Ying-Ru Chen for kindly sharing her sampling methods and experiences; Dr. Yi-zhu Chen and Dr. Shu-ling Lin for discussing their views regarding the phenology in Guangzhou; and Dr. Stella Wang for editing our manuscript with skill and helpful advice. This study was supported by grant NSC 99-2923-B-002-001-MY3 from the National Science Council.

\section{Author details}

${ }^{1}$ Institute of Ecology and Evolutionary Biology, National Taiwan University, No. 1, Sec. 4, Roosevelt Rd., Taipei 10617, Taiwan. ${ }^{2}$ Department of Forestry, National Chung Hsing University, No. 250 Kuokwang Rd., Taichung 40227, Taiwan.
Received: 21 February 2012 Accepted: 26 December 2012

Published: 21 August 2013

\section{References}

Ahmed S, Compton SG, Butlinc RK, Gilmartina PM (2009) Wind-borne insects mediate directional pollen transfer between desert fig trees 160 kilometers apart. PNAS 106:20342-20347

Ando K, Inoue R, Maeto K, Tojo S (2006) Effects of temperature on the life history traits of endoparasitoid Microplitis manilae Ashmead (Hymenoptera: Braconidae), parasitizing the larvae of the common cutworm, Spodoptera litura Fabricius (Lepidoptera: Noctuidae). Japn J Appl Entomol Zool 50:201-210

Anstett MC, Michaloud G, Kjellberg F (1995) Critical population size for fig/wasp mutualism in a seasonal environment - effect and evolution of the duration of female receptivity. Oecologia 103:453-461

Anstett MC, Hossaert-McKey M, McKey D (1997) Modeling the persistence of small populations of strongly interdependent species: Figs and fig wasps. Conserv Bio 11:204-213

Bain A (2012) Colonization and adaptations of Ficus in Taiwan, PhD thesis. National Taiwan University, Taipei, Taiwan, p 288

Beardsley WJ (1998) Chalcid wasps (Hymenoptera: Chalcidoilea) associated with fruit of Ficus microcarpa in Hawaii. Proc Hawaii Entomol Soc 33:19-34

Berg CC, Corner EJH (2005) Moraceae -Ficus. In: Nooteboom HP (ed) Flora Malesiana, Ser. I, Vol. 17, Part 2. National Herbarium Nederland, Leiden

Bronstein JL (1995) Hurricane-Andrew and a Florida fig pollination mutualism resilience of an obligate interaction. Biotropica 27:373-381

Bronstein JL, Hossaert-McKey M (1996) Variation in reproductive success within a subtropical fig pollinator mutualism. J Biogeogr 23:433-446

Bronstein JL, Patel A (1992) Temperature-sensitive development - consequences for local persistence of 2 subtropical fig wasp species. Am Midl Nat 128:397-403

Bronstein JL, Gouyon PH, Gliddon C, Kjellberg F, Michaloud G (1990) The ecological consequences of flowering asynchrony in monoecious figs: a simulation study. Ecology 71:2154-2156

Chen YR (2001) Population fluctuation and community ecology of Ficus microcarpa L.f. and its fig wasps, PhD thesis. National Taiwan University, Taipei, Taiwan, p 185 [in Chinese with English summary]

Chen YR, Chuang WC, Wu WJ (1999) Chalcid wasps on Ficus microcarpa L.f. in Taiwan (Hymenoptera: Chalcidoidea). J Taiwan Mus 52:39-79

Chen YR, Chou LS, Wu WJ (2001) Regulation of fig wasps entry and egress: the role of ostiole of Ficus microcarpa L.f. Formosan Entomol 21:171-182

Chen YR, Wu WJ, Chou LS (2004) Synchronization of fig (Ficus microcarpa L.f.) abundance and pollinator (Eupristina verticillata: Agaoninae) population dynamics in northern Taiwan. J Natl Taiwan Mus 57:23-35

Chew WL (1989) 'Moraceae', Flora of Australia, Vol 3. Australian Government Publishing Service, Canberra, pp 15-68

Compton SG, Ellwood MDF, Davis AJ, Welch K (2000) The flight heights of chalcid wasps (Hymenoptera, Chalcidoidea) in a lowland Bornean rain forest: Fig wasps are the high fliers. Biotropica 32:515-522

Corlett RT (1984) The phenology of Ficus benjamina and Ficus microcarpa in Singapore. J Singapore Nat Aca Sci 13:30-31

Cruaud A, Roula J-Z, Genson G, Cruaud C, Couloux A, Kjellberg F, van Noort S, Rasplus J-Y (2010) Laying the foundations for a new classification of Agaonidae (Hymenoptera: Chalcidoidea), a multilocus phylogenetic approach. Cladistics 26:359-387

Dhillon MK, Sharma HC (2009) Temperature influences the performance and effectiveness of field and laboratory strains of the ichneumonid parasitoid, Campoletis chlorideae. BioControl 54:743-750

Doğanlar M (2012) Occurrence of fig wasps (Hymenoptera: Chalcidoidea) in Ficus carica and F. microcarpa in Hatay, Turkey, Turk. J Zool 36:721-724

Dunn DW, Yu DW, Ridley J, Cook JM (2008) Longevity, early emergence and body size in a pollinating fig wasp - implications for stability in a figpollinator mutualism. J Anim Ecol 77:927-935

Durant JM, Hjermann DO, Ottersen G, Stenseth NC (2007) Climate and the match or mismatch between predator requirements and resource availability. Clim Res 33:271-283

Ellis RH (2011) Rice seed quality development and temperature during late development and maturation. Seed Sci Res 21:95-101

Figueiredo RA, Motta Junior JC, Vasconcellos LADS (1995) Pollination, seed dispersal, seed germination and establishment of seedlings of Ficus microcarpa, Moraceae, in southeastern Brazil. Rev Bras Biol 55:233-239

Galil J, Eisikowitch D (1968) On the pollination ecology of Ficus sycomorus in East Africa. Ecology 49:259-269 
Gibernau M, Hossaert-McKey M, Anstett MC, Kjellberg F (1996) Consequences of protecting flowers in a fig: a one-way trip for pollinators? J Biogeogr 23:425-432

Gibernau M, Hossaert-McKey M, Frey J, Kjellberg F (1998) Are olfactory signals sufficient to attract fig pollinators? Ecoscience 5:306-311

Grison-Pigé L, Bessiere JM, Hossaert-McKey M (2002) Specific attraction of fig-pollinating wasps: Role of volatile compounds released by tropical figs. J Chem Ecol 28:283-295

Harrison RD (2001) Drought and the consequences of El Niño in Borneo: a case study of figs. Popul Ecol 43:63-75

Harrison RD, Rasplus JY (2006) Dispersal of fig pollinators in Asian tropical rain forests. J Trop Ecol 22:631-639

Hill DS (1967) Figs of Hong Kong. Hong Kong University Press, Hong Kong

Hossaert-McKey M, Gibernau M, Frey JE (1994) Chemosensory attraction of fig wasps to substances produced by receptive figs. Entomol Exp Appl 70:185-191

Hsieh MC (1992) The symbiosis between fig wasps and Ficus microcarpa L.f, MS thesis. National Taiwan University, Taipei, Taiwan, p 51 [in Chinese with English summary]

Hu S, Dilcher DL, Jarzen DM, Taylor DW (2008) Early steps of angiosperm pollinator coevolution. PNAS 105:240-245

Jonzen N, Hedenstrom A, Lundberg P (2007) Climate change and the optimal arrival of migratory birds. Proc R Soc Biol Sci Ser B 274:269-274

Kalin Arroyo MT, Armesto JJ, Primack RB (1985) Community studies in pollination ecology in the high temperate Andes of central Chile II. Effect of temperature on visitation rates and pollination possibilities. Plant Syst Evol 149:187-203

Kaufmann S, Mckey D, Hossaert-Mckey M, Horvitz CC (1991) Adaptations for a two-phase seed dispersal system involving vertebrates and ants in a hemiepiphytic fig (Ficus microcarpa: Moraceae). Am J B 78:971-977

Kjellberg F, Gouyon P-H, Ibrahim M, Raymond M, Valdeyron G (1987) The stability of the symbiosis between dioecious figs and their pollinators: a study of Ficus carica. and Blastophaga psenes. Evolution 41:693-704

Kjellberg F, Doumesche B, Bronstein JL (1988) Longevity of a fig wasp (Blastophaga psenes). Proc K Ned Akad Wet Ser C Biol Med Sci 91:117-122

Kjellberg F, Jousselin E, Hossaert-Mckey M, Rasplus J-Y (2005) Biology, Ecology, and Evolution of Fig-pollinating Wasps (Chalcidoidea, Agaonidae). In: Raman A, Schaefer CW, Withers TM (eds) Biology, Ecology and Evolution of Gallinducing arthropods. Volume 2. inc., Enfield, New Hampshire

Lin SL, Zhao NX, Chen YZ (2008) Phenology and the production of seeds and wasps in Ficus microcarpa in Guangzhou, China. Symbiosis 45:101-105

Martin TE (2007) Climate correlates of 20 years of trophic changes in a high-elevation riparian system. Ecology 88:367-380

McKey D (1989) Population biology of figs: applications for conservation. Experientia 45:661-673

McPherson JR (2005a) Phenology of six Ficus L., Moraceae, species and its effects on pollinator survival, in Brisbane, Queensland, Australia. Geogr Res 43:297-305

McPherson JR (2005b) A recent expansion of its Queensland range by Eupristina verticillata, Waterston (Hymenoptera, Agaonidae, Agaoninae), the pollinator of Ficus microcarpa L.f. (Moraceae). Proc Linn Soc N S W 126:197-201

Nadel H, Frank JH, Knight RJ Jr (1992) Escapees and accomplices:the naturalization of exotic Ficus and their associated faunas in Florida. Fla Entomol 75:29-38

Peres-Neto PR, Jackson DA, Somers KM (2003) Giving meaningful interpretation to ordination axes: Assessing loading significance inprincipal component analysis. Ecology 84:2347-2363

Proffit M, Schatz B, Bessiere JM, Chen C, Soler C, Hossaert-McKey M (2008) Signalling receptivity: Comparison of the emission of volatile compounds by figs of Ficus hispida before, during and after the phase of receptivity to pollinators. Symbiosis 45:15-24

R Development Core Team (2009) R: a Language and Environment for Statistical Computing. R Foundation for Statistical Computing, Vienna, Austria

Shanahan M, So S, Compton SG, Corlett R (2001) Fig-eating by vertebrate frugivores: a global review. Bio Rev 76:529-572

Spencer H, Weiblen G, Flick B (1996) Phenology of Ficus variegata in a seasonal wet tropical forest at Cape Tribulation, Australia. J Biogeogr 23:467-475

Thien LB, Bernhardt P, Devall MS, Chen ZD, Luo YB, Fan JH, Yuan LC, Williams JH (2009) Pollination biology of basal angiosperms (ANITA grade). Am J Bot 96:166-182

Tzeng HY (2004) Taxonomic study of the genus Ficus in Taiwan, PhD thesis. National Chung-Hsing University, Taichung, Taiwan, p 421 [in Chinese with English summary]
Tzeng HY, Tseng LJ, Ou CH, Lu FY (2005) Phenology of Ficus formosana Maxim at Guandaushi forest ecosystem. Q J Chin For 38:377-395

Tzeng HY, Lu FY, Ou CH, Lu KC, Tseng LJ (2006) Pollinational-mutualism strategy of Ficus erecta var. beecheyana and Blastophaga nipponica in seasonal Guandaushi Forest Ecosystem, Taiwan. Bot Studies 47:307-318

van Noort S, Compton SG (1996) Convergent evolution of agaonine and sycoecine (Agaonidae, Chalcidoidea) head shape in response to the constraints of host fig morphology. J Biogeogr 23:415-424

Visser ME, Both C (2005) Shifts in phenology due to global climate change: the need for a yardstick. Proc R Soc Lond B 272:2561-2569

Wang RW, Sun BF (2009) Seasonal change in the structure of fig-wasp community and its implication for conservation. Symbiosis 47:77-83

Wang XF, Peng YQ, Yang DR (2005) The reproductive charecters of Ficus hispita L. J Yunnan Agric Univ 60:632-635

Wang RW, Ridley J, Sun BF, Zheng Q, Dunn DW, Cook J, Shi L, Zhang YP, Yu DW (2009) Interference competition and high temperatures reduce the virulence of fig wasps and stabilize a fig-wasp mutualism. PLoS ONE 4:e7802

Wiebes JT (1979) Co-evolution of figs and their insect pollinators. Annu Rev Ecol Syst 10:1-12

Willmer PG (1983) Thermal constraints on activity patterns in nectar-feeding insects. Ecol Ent 8:455-469

Willmer PG (1985) Size effects on the hygrothermal balance and foraging patterns of a sphecid wasp, Cerceris arenaria. Ecol Ent 10:469-479

Winder M, Schindler DE (2004) Climate change uncouples trophic interactions in an aquatic ecosystem. Ecology 85:2100-2106

Wright J, van Schaik CP (1994) Light and the phenology of tropical trees. Am Nat 143:192-199

Yang HW (2011) Variation in the phenology and population interactions between Ficus microcarpa L.f. and its pollinating wasp, Eupristina verticillata, MS thesis. National Taiwan University, Taipei, Taiwan, p 101

Zimmerman JK, Wright SJ, Calderón O, Pagan MA, Paton S (2007) Flowering and fruiting phenologies of seasonal and aseasonal neotropical forest: the role of annual changes in irradiance. J Trop Ecol 23:231-251

doi:10.1186/1999-3110-54-11

Cite this article as: Yang et al:: Phenology and pollinating wasp

dynamics of Ficus microcarpa L.f.: adaptation to seasonality. Botanical Studies 2013 54:11.

\section{Submit your manuscript to a SpringerOpen ${ }^{\circ}$ journal and benefit from:}

- Convenient online submission

Rigorous peer review

- Immediate publication on acceptance

- Open access: articles freely available online

- High visibility within the field

- Retaining the copyright to your article

Submit your next manuscript at springeropen.com 